\title{
Morphometric Analysis of the Relationship between Bigonial Width and Cranium
}

\author{
Seda Sertel Meyvaci ${ }^{1^{*}}$, Mustafa Hizal $^{2}$ \\ ${ }^{1}$ Bolu Abant İzet Baysal University, Faculty of Medicine, Department of Anatomy, Bolu, \\ Turkey. \\ ${ }^{2}$ Bolu Abant İzet Baysal University, Faculty of Medicine, Department of Radiology, Bolu, \\ Turkey.
}

\begin{abstract}
In the present study, the purpose was to determine the relation between bigonial width and craniometric parameters. In this study, seven craniometric parameters were examined based on computed tomography images of 110 adult individuals 58 of whom were males and 52 females. These parameters were Bigonial Width $(B G W)$ in mandible, and Maximum Cranium Width (MCW), Upper Face Width (UFW), Bizygomatic Width (BZW), Vertex-Prosthion Height (VPH), Vertex-Nasion Height (VNH), Upper Face Height (UFH) in the cranium. The difference between two groups was examined with $\mathrm{t}$-test in independent groups. The relation between numerical variables was examined with the Pearson Correlation Coefficient. The analyses were made with IBM SPSS v.21. The significance level was taken as $p<0.05$. When the morphometric relationship between the mandible and cranium was examined, it was found that although a relation was detected between $B G W$ and all craniometric parameters, there was a relation between $B G W$ and MCW, UFW, BZW in male, and UFW and BZW parameters in females when gender was taken into account $(p<0.05)$. No significant correlations were detected between $B G W$ and VPH, VNH, UFH measurement values in both genders. This study revealed that there is a significant relation between $B G W$ and $U F W$ and BZW parameters in both genders. It is considered that the relation between the mandible and cranium can be used in the clinic when it should be considered, and the results will contribute to scientific studies.
\end{abstract}

Key words: Bigonial width, Mandible, Cranium, Compatibility, Computed tomography

\footnotetext{
* Corresponding author: Seda Sertel Meyvac1, Bolu Abant İzzet Baysal University, Faculty of Medicine, Department of Anatomy, Gölköy Campus 14030 Bolu, E-mail: sedasertelmeyvaci@ gmail.com, ORCID ID: 00000002-9450-145X .
} 


\section{Introduction}

The mandible, which is a facial bone, is the movable part of the cranium, and temporal bone and temporomandibular joint allow the chewing movements of the mandible $(1,2)$. In joint biomechanics, when maximum chewing pressure is applied to the occlusal surfaces, this chewing pressure is transferred to the viscerocranium from the teeth, then to the basis cranii and cranium (3). With the transfer of this pressure, it is important with a clinical and anthropological viewpoint to understand how and to what extent the forces applied by chewing muscles affect the mandibular shape (4).

The fact that the mandible is one of the skeletal components of the cranium, and it was found as a separate bone in skeletal remains led to morphological and morphometric studies regarding this bone $(5,6)$. The mandible, which is the largest and hardest facial bone, has come to the forefront in studies conducted to identify gender as an important source of personal identification, since it keeps its integrity, usually because of its resistance to postmortem damages (7).

The important position of the mandible on the face was evaluated in studies in terms of its aesthetic, sexually dimorphic, and anthropometric aspects as a part of important functions, such as eating and as a bone very easy to recognize among skeletal remains $(8,9)$. When previous morphometric studies were examined, it was seen that mostly the metrical and angular parameters of the mandible were examined $(10,11)$. It was also found that the focus was on the gonion area of the mandible, the holding place of the chewing muscles, and the parameters of bigonial angle and bigonial width (12-15).
Although limited studies examined craniometric parameters, it was found that the relation between these parameters was not evaluated $(8,15,16)$. In a previous study that evaluated cranium compatibility with the mandible, it was found that a small number of linear parameters were evaluated and were transverse only (17).

Although there are studies that investigated the morphometric features of mandible and cranium, studies that examine relations between these parameters are limited. The purpose of the present study was to evaluate the transverse and vertical parameters of the relations between bigonial width and cranium by using Computed Tomography (CT) results.

\section{Material and methods}

The images of 58 male and 52 female adult individuals who underwent head CT in the Department of Radiology of Bolu Abant Izzet Baysal University, Faculty of Medicine were examined retrospectively in the present study. The individuals who had cranium integrity and no diseases that affected their bone structures, and with no bone anomalies in CT images were included in the study. The present study was approved by Bolu Abant Izzet Baysal University, Clinical Researches Ethics Committee, with the Decision Number 2021/54.

\section{Computed Tomography Protocol}

All patients underwent CT using a 64-slice Multi-Detector Computed Tomography (MDCT) device (Revolution EVO, GE healthcare, Waukesha, WI, the USA) with the same examination protocol using $64 \times 0.5 \mathrm{~mm}$ collimation scanner with a gantry rotation speed of $400 \mathrm{~ms} /$ rotation, range of box 450-500, image thickness 5 
$\mathrm{mm}$, standard pitch factor of 0.641, reconstruction interval $0.625 \mathrm{~mm}$ and a total exposure time 11. Each scan was obtained with a tube voltage of $120 \mathrm{KV}$ and $320 \mathrm{mAs}$. Images have been transferred to a separate workstation (GE, Advantage Workstation 4.4) for measurements.

Obtaining Measurements of Parameters

Gonion (go), euryon (eu), frontomalar temporal (fmt), zygion (zy), nasion (n), prosthion (pr) and vertex anatomical landmarks were used in the measurement of our parameters. In the present study, seven different parameters were evaluated to determine the morphometric relations between horizontal and vertical parameters, such as bigonial width in mandible, and maximum cranium width, upper face width, bizygomatic width, vertex-prosthion height, vertex-nasion height, upper face height in the cranium, by referencing these anatomical landmarks (16, 18, 19) (Figure 1). All parameters were measured by 2 different people in 3 repetitions.

Measured parameters, abbreviations and related landmarks

\section{Measurement name}

1 Bigonial width

2 Maximum cranium width

3 Upper face width

4 Bizygomatic width

5 Vertex-prosthion height

6 Vertex-nasion height

7 Upper face height

Abbreviation
BGW
MCW
UFW
BZW
VPH
VNH
UFH

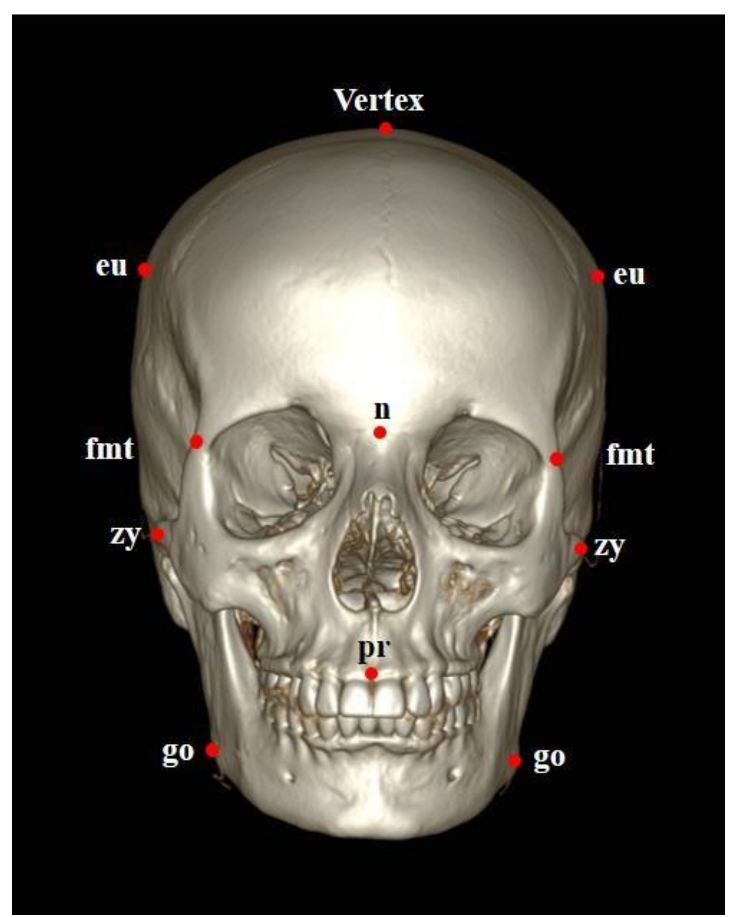

Figure 1: Frontal view of cranium showing anatomical landmarks used in the present study. 


\section{Statistical Analyses}

Mean and Standard Deviation (SD) values were given for numeric variables, and numbers and percentage values were given for categorical variables in defining the data. Normality assumption was examined with the Kolmogorov-Smirnov Test. Whether there were significant differences between two groups was evaluated with the $\boldsymbol{t}$-Test in Independent Groups. The relations between numerical variables were examined with the Pearson Correlation Coefficient. Coefficient correlation 0.0 0.30 were interpreted as negligible, those $0.31-0.50$ as low, those $0.51-0.70$ as moderate, $0.71-0.9$ as strong and $0.91-$ 1.0 as very strong. Analyses were made with IBM SPSS v.21. The significance level was taken as $\mathrm{p}<0.05$.

\section{Results}

The CT images of 110 individuals, including 58 males with a mean age of $51.59 \pm 12.96$ and 52 females with a mean age of $52.29 \pm 14.08$, were evaluated retrospectively in our study. When gender groups (male $52.7 \%$, female $47.3 \%$ ) were evaluated, no significant differences were detected in terms of age $(p=0.786)$. The demographic characteristics of the individuals who participated in the study are given in Table 1.

Table 1: Demographic characteristics of individuals.

\begin{tabular}{llccc}
\hline & & Number $(\boldsymbol{\%})$ & Age & p \\
\hline Gender & Female & $52(47.3)$ & $52.29 \pm 14.08$ & 0.786 \\
& Male & $58(52.7)$ & $51.59 \pm 12.96$ & \\
\hline & Total & $110(100.0)$ & $51.92 \pm 13.44$ &
\end{tabular}

When the measurement parameters between gender groups were examined, it was found that there were significant differences in BGW, MCW, UFW, BZW,
VPH, VNH and UFH values $(\mathrm{p}<0.001)$. It was found that the measurement values of all parameters were higher in male individuals (Table 2).

Table 2: Evaluation of parameters' measurement values according to gender.

\begin{tabular}{lccc}
\hline & Male $(\mathbf{n}=\mathbf{5 8})$ & Female $(\mathbf{n}=\mathbf{5 2})$ & \\
\hline Mean \pm SD & Mean \pm SD & p \\
\hline MCW & $106.01 \pm 7.42$ & $97.67 \pm 6.48$ & $<\mathbf{0 . 0 0 1}$ \\
\hline UFW & $151.81 \pm 7.17$ & $146.44 \pm 5.81$ & $<\mathbf{0 . 0 0 1}$ \\
\hline BZW & $108.99 \pm 4.79$ & $104.52 \pm 4.35$ & $<\mathbf{0 . 0 0 1}$ \\
\hline VPH & $137.62 \pm 6.19$ & $128.31 \pm 5.05$ & $<\mathbf{0 . 0 0 1}$ \\
\hline VNH & $172.33 \pm 8.21$ & $164.70 \pm 7.76$ & $<\mathbf{0 . 0 0 1}$ \\
\hline UFH & $98.29 \pm 6.76$ & $94.63 \pm 5.42$ & $<\mathbf{0 . 0 0 1}$ \\
\hline
\end{tabular}


The morphometric relations between BGW in mandible and MCW, UFW, BZW, VPH, $\mathrm{VNH}$, UFH parameters in cranium were examined in our study. It was found that there was a strong relation between BGW and VPH measurement values, a moderate relation with BZW, and a low relation with MCW, UFH, and a negligible and low relation with VNH (Table 3).

Table 3: Relation between bigonial width and craniometric parameters' measurement values.

\begin{tabular}{lcc}
\hline & \multicolumn{2}{c}{ BGW } \\
\hline MCW & r & p \\
\hline UFW & 0.462 & $<\mathbf{0 . 0 0 1}$ \\
\hline BZW & 0.635 & $<\mathbf{0 . 0 0 1}$ \\
\hline VPH & 0.747 & $<\mathbf{0 . 0 0 1}$ \\
\hline VNH & 0.362 & $<\mathbf{0 . 0 0 1}$ \\
\hline UFH & 0.201 & $\mathbf{0 . 0 3 5}$ \\
\hline
\end{tabular}

When the relation between bigonial width and measurement values of craniometric parameters were examined according to gender, it was found that there was a strong relation between $\mathrm{BGW}$ and $\mathrm{BZW}$ in males, a moderate relation with UFW, and a low relation with $\mathrm{MCW}$. Although there were moderate relations between BZW and UFW in females, the relation that was detected in MCW in males was not detected in females. It was also found that there were no correlations among VPH, $\mathrm{VNH}, \mathrm{UFH}$ and BGW measurement values in males and females (Table 4).

Table 4:Relation between bigonial width and craniometric parameters' measurement values according to gender.

\begin{tabular}{lcccc}
\hline & \multicolumn{2}{c}{ Female } & \multicolumn{2}{c}{ Male } \\
\hline & & $\mathbf{B G W}$ & & $\mathbf{p}$ \\
\hline MCW & 0.209 & 0.138 & 0.416 & $\mathbf{0 . 0 0 1}$ \\
\hline UFW & 0.525 & $<\mathbf{0 . 0 0 1}$ & 0.535 & $<\mathbf{0 . 0 0 1}$ \\
\hline BZW & 0.508 & $<\mathbf{0 . 0 0 1}$ & 0.715 & $<\mathbf{0 . 0 0 1}$ \\
\hline VPH & 0.164 & 0.247 & 0.192 & 0.148 \\
\hline VNH & 0.087 & 0.541 & 0.052 & 0.697 \\
\hline UFH & 0.211 & 0.133 & 0.224 & 0.091
\end{tabular}

\section{Discussion}

The main purpose of the present study was to examine the relation between the measurement values of the mandible's BGW and craniometric parameters with $\mathrm{CT}$. The relation between the cranium is important because the mandible has several specific anatomical features, with aesthetic importance with facial bone, and due to the possibility of a matching when a separated cranium and mandible are found in skeletal remains with have impaired integrity (17, 20, 21).

When the studies conducted on mandible were examined, it was found that the parameters were evaluated directly with dry bones with the help of caliper and radiological images $(9,17,20)$. We also 
found that the cases used in previous studies were examined in different populations by considering the age and gender data $(11,14,22)$.

When previous studies in which mandible and craniometric parameters were evaluated together were examined, 63 males were evaluated with a mean age of $48 \pm 15.5$, and 57 females with a mean age of $47 \pm 15.7$ with CT images. The BGW, BZW, UFH measurement values were found to be $94.94 \pm 7.12 \mathrm{~mm} ; 87.52 \pm 5.25$ $\mathrm{mm}, 131.73 \pm 5.20 \mathrm{~mm} ; 122.73 \pm 4.08 \mathrm{~mm}$, $73.15 \pm 5.41 \mathrm{~mm}$; and $69.37 \pm 4.24 \mathrm{~mm}$ in males and females, respectively. Although it was found that there was a difference in these parameters between the gender groups $(\mathrm{p}<0.001)$, the relation between mandible and cranium morphometry was not examined in this study (16). In our study, BGW, BZW, and UFH values with the help of CT were determined to be $106.01 \pm 7.42 \mathrm{~mm} ; \quad 97.67 \pm 6.48 \mathrm{~mm}$, $137.62 \pm 6.19 \mathrm{~mm} ; \quad 128.31 \pm 5.05 \mathrm{~mm}$, $73.56 \pm 5.66 \mathrm{~mm} ; \quad 69.31 \pm 5.72 \mathrm{~mm}$, respectively in males with an average age of $51.59 \pm 12.96$ and females with a mean age $52.29 \pm 14.08$. It was also found that there was a difference between gender groups in terms of measurement values $(\mathrm{p}<0.001)$; and the relation between BGW and craniometric parameters was examined in our study. A moderate and significant relation was detected between BGW measurement value and BZW measurement value $(\mathrm{r}=0.635 ; \mathrm{p}<0.001)$, and low and significant relation was detected with UFH measurement value $(\mathrm{r}=0.356 ; \mathrm{p}<0.001)$.

When we compared our results with the study of Gillet $C$ et al. (16), it was found that BGW and BZW value was high in our study, and UFH value was similar. It was found that it is similar in these studies that there were differences between gender groups in terms of measurement values of these parameters in both studies. We believe that the lack of similarity in BGW and BZW values maybe because of ethnic differences, although the mean age of the cases was similar. The relation between mandible and cranium morphometry was not examined in the study conducted by Gillet $\mathrm{C}$ et al. (16).

In a study evaluating the cranium for the Caucasian race in males and females with a mean age of (approximately) 40, the following results were found; MCW $139.6 \pm 5.70 \mathrm{~mm} ; 137.5 \pm 4.75 \mathrm{~mm}, \mathrm{BZW}$, $128.9 \pm 4.27 \mathrm{~mm} ; 122.0 \pm 3.47 \mathrm{~mm}, \mathrm{UFH}$, $71.2 \pm 3.82 \mathrm{~mm} ; 66.0 \pm 4.96 \mathrm{~mm}$ and BGW $99.9 \pm 5.71 \mathrm{~mm} ; 92.1 \pm 5.17 \mathrm{~mm}$. The relation between $\mathrm{BGW}$ and craniometric parameters was not evaluated in this study (23). When the results of this study were compared with those of Iscan et al., the measurement values of parameters were MCW 151.81 $\pm 7.17 \mathrm{~mm} ; 146.44 \pm 5.81 \mathrm{~mm}$, BZW, $137.62 \pm 6.19 \mathrm{~mm} ; 128.31 \pm 5.05 \mathrm{~mm}$, UFH, $73.56 \pm 5.66 \mathrm{~mm} ; 69.31 \pm 5.72 \mathrm{~mm}$ and BGW 106.01 $\pm 7.42 \mathrm{~mm}$; 97.67 \pm 6.48 $\mathrm{mm}$ and the mean age of $51.92 \pm 13.44$ in our study in males and females who had a mean age of $51.92 \pm 13.44$. Although this study was conducted directly on dry bones, and our study was conducted with the CT method, it was reported that the data obtained with these two different methods can be compared safely (24). We believe that these differences may have stemmed from the mean age difference in studies and that these studies were not conducted in the same populations.

The relation between BGW measurement value and craniometric measurement values was examined in our study; and as a result, strong relation was found with VPH $(\mathrm{r}=0.747 ; \mathrm{p}<0.001)$, a moderate relation 
with BZW ( $r=0.635 ; \mathrm{p}<0.001)$, and a low relation with $\mathrm{MCW}(\mathrm{r}=0.462 ; \mathrm{p}<0.001)$, UFH $(r=0.356 ; p<0.001)$, and a negligible and low relation with $\mathrm{VNH} \quad(\mathrm{r}=0.201$; $\mathrm{p}=0.035$ ). When this relation was examined according to gender, it was found that there was a strong relation $(\mathrm{r}=0.715 ; \mathrm{p}<0.001)$ between BGW and BZW in males, a moderate relation between UFW ( $r=0.535 ; \mathrm{p}<0.001)$, and low relation between $\mathrm{MCW} \quad(\mathrm{r}=0.416$; $\mathrm{p}=0.001)$. A moderate relation was detected in females between BGW and BZW and UFW ( $r=0.508 ; \mathrm{p}<0.001$, $\mathrm{r}=0.525 ; \mathrm{p}<0.001$, respectively). Although the mandible and cranium were examined morphometrically in studies, the fact that the relation of these parameters was not examined with each other prevents the comparability of our study results $(16,23)$.

\section{Conclusion}

The results of our showed found that there are relations among $\mathrm{BGW}$ and $\mathrm{MCW}$, UFW, BZW, VPH, VNH, UFH

parameters; however, when gender was taken into account, there was a relation between BGW and MCW, UFW, BZW in males, and UFW and BZW parameters in females. When the mandible is found as a bone separated from the cranium in skeletal remains, the morphometric relation between the mandible and the cranium is important, also for facial reconstruction surgeries and the design of the appropriate mandible for forensic facial reconstruction. For this reason, we recommend that the number of parameters that will be investigated in the mandible and cranium is increased when future clinical trials are planned and that this relation is examined and modeled again in the relations identified here.

\section{Conflict of interests}

The authors declare no conflict of interests.

\section{Acknowledgement}

Researchers attributed equally to the study.

\section{References}

1. Acar M, Alkan SB, Tolu I, et al. Morphometric analysis of mandibula with MDCT method in Turkish population. Asian J Biomed Pharm Sci. 2017;7:13-5.

2. Hu KS, Koh KS, Han $\mathrm{SH}$, et al. Sex determination using nonmetric characteristics of the mandible in Koreans. JForensic Sci. 2006;51: 1376-82. https://doi.org/10.1111/j.15564029.2006.00270.x.

3. Winkler S, Dalkowski K, Mair J, et al. Sobotta lehrbuch anatomie. Germany: Elsevier Health Sciences; 2015.

4. Sella-Tunis T, Pokhojaev A, Sarig R, et al. Human mandibular shape is associated with masticatory muscle force. Sci Rep. 2018;8:1-10. https://doi.org/10.1038/s41598-018-24293-3.

5. Mangla R, Dua V, Khanna M, Singh N, et al. Evaluation of mandibular morphology in different facial types. Contemp Clin Dent. 2011;2:200. https://doi.org/10.4103/0976237x.86458.

6. Sharma M, Gorea RK, Gorea A, et al. A morphometric study of the human mandible in the Indian population for sex determination. Egypt $\mathbf{J}$ Forensic Sci. 2016;6:165-9. https://doi.org/10.1016/j.ejfs.2015.01.002.

7. Kallalli B, Rawson K, Ramaswamy V, et al. Sex determination of human mandible using metrical parameters by computed tomography: A prospective radiographic short study. J Indian Acad Oral Med Radiol. 2016;28:7. https://doi.org/10.4103/0972-1363.189990.

8. Hossain MG, Saw A, Alam R, et al. Multiple regression analysis of anthropometric measurements influencing the cephalic index of male Japanese university students. Singapore Med J. 2013; 54:516-20. https://doi.org/10.11622/smedj.2013175.

9. Kumar M, Lokanadham S. Sex determination \& morphometric parameters of human mandible. Int J Res Med Sci. 2013;1:93. https://doi.org/10.5455/2320-6012.ijrms20130511. 10. Vinay G, Mangala Gowri SR, Anbalagan J. Sex determination of human mandible using metrical parameters. J Clin Diagnostic Res. 
2013;7:2671-3.

https://doi.org/10.7860/JCDR/2013/7621.3728.

11. Kim YH, Kang SJ, Sun H. Cephalometric angular measurements of the mandible using threedimensional computed tomography scans in koreans. Arch Plast Surg. 2016;43:32-7. https://doi.org/10.5999/aps.2016.43.1.32.

12. Amin WM. Osteometric assessment of various mandibular morphological traits for sexual dimorphism in jordanians by discriminant function analysis. Int J Morphol. 2018;36:642-50. https://doi.org/10.4067/S0717-

95022018000200642.

13. Tunis TS, Sarig R, Cohen H, et al. Sex estimation using computed tomography of the mandible. Int J Legal Med. 2017;131:1691-700. https://doi.org/10.1007/s00414-017-1554-1.

14. Al-habahbah A. Age and gender differences in gonial angle, ramus height and bigonial width in dentate subjects. Pakistan Oral Dent J. 2012;32:81-7.

15. Naikmasur VG, Shrivastava R, Mutalik S. Determination of sex in South Indians and immigrant Tibetans from cephalometric analysis and discriminant functions. Forensic Sci Int. 2010;197:122.e1-122.e6.

https://doi.org/10.1016/j.forsciint.2009.12.052.

16. Gillet C, Costa-Mendes L, Rérolle C, et al. Sex estimation in the cranium and mandible: a multislice computed tomography (MSCT) study using anthropometric and geometric morphometry methods. Int J Legal Med. 2020:823-32. https://doi.org/10.1007/s00414-019-02203-0.

17. Preissler S, Verhoff MA, Ramsthaler F, et al. Morphometric investigations to assess the compatibility of mandible and skull.

ForensicSci Int. 2018;286:193-8. https://doi.org/10.1016/j.forsciint.2018.03.013.

18. Mahakkanukrauh P, Sinthubua A, Prasitwattanaseree $\mathrm{S}$, et al. Craniometric study for sex determination in a Thai population. Anat Cell Biol. 2015;48:275-83. https://doi.org/10.5115/acb.2015.48.4.275.

19. Sertel Meyvaci S, Kosif R, Bamaç B, et al. Evaluation of apertura piriformis and related cranial anatomical structures through computed tomography: Golden ratio. Folia Morphol. 2019;78:839-46. https://doi.org/10.5603/FM.a2019.0021.

20. Apaydin B, Icoz D, Yasar F, et al. Evaluation of mandibular anatomical formation for gender determination in Turkish population. Balk $\mathbf{J}$ Dent Med. 2018;22:133-7. https://doi.org/10.2478/bjdm-2018-0023.

21. Hofer S, Payne C. Functional and aesthetic outcome enhancement of head and neck reconstruction through secondary procedures. Semin Plast Surg. 2010;24:309-18. https://doi.org/10.1055/s-0030-1263072.

22. Pereira JGD, Lima KF, Da Silva RHA. Mandibular measurements for sex and age estimation in brazilian sampling. Acta Stomatol Croat. 2020;54:294-301.

https://doi.org/10.15644/asc54/3/7.

23. Iscan MY, Steyn M. Craniometric determination of population affinity in South Africans. J Clin Forensic Med. 1999;6:258-9. https://doi.org/10.1016/s1353-1131(99)90011-1.

24. Naderi S, Çakmakçi H, Acar F, et al. Anatomical and computed tomographic analysis of C1 vertebra. Clin Neurol Neurosurg. 2003;105:245-8. https://doi.org/10.1016/S03038467(03)00037-4. 